\title{
Letter to the Editor
}

\section{Premonitions of What Could Have Been}

To the Editor:

We owe a debt of thanks to Barbara A. Walker, William J. Serdahely, and Lori J. Bechtel (1991) for calling our attention to what they claimed to be a previously unreported type of precognitive vision associated with near-death experiences (NDEs): seeing the reaction of one's family members to the news of one's death. In commenting on the three instructive case histories they presented to illustrate this phenomenon, they observed that they "know of no other previous accounts in the literature of a near-death prophetic case in which the experiencer was able to view the possible emotional aftereffects of his or her death on parents and loved ones" (p. 93). But, in fact, such cases do exist and are to be found, interestingly enough, among the earliest examples of NDEs for which we have written first-person narratives.

For one instance, consider the famous example of the English Admiral Francis Beaufort, who had an NDE when a young man in 1791 as a result of a near-drowning incident. This case is especially noteworthy because it was the first in the literature, so far as I know, to use the phrase "panoramic review" in connection with the detailed life review aspect of the near-death episode. However, Beaufort did not only have a memory playback of past events; he also seemed to have had a clear presentiment of what effect his death would have. In writing many years later of this portion of his NDE, Beaufort commented:

The course of these thoughts I can even now in a great measure retrace-the event which had just taken place, the awkwardness that produced it, the bustle it must have occasioned, the effect it would have on a most affectionate father . . . (Audette, 1982, p. 32)

Of course, it may be argued that this is scarcely more than an intimation of the precognition that Walker, Serdahely, and Bechtel 
were concerned with in their article, and I would agree, but for a clearcut example, fully commensurate with theirs, consider another celebrated case from the first major study of NDEs, now a century old.

Albert Heim was a Swiss geology professor who was fond of climbing in the Alps. One day, he lost his balance, fell off a cliff, and hurtled toward what he thought was certain death. Like Beaufort, Heim had a life review-and preview. In his own words:

My sisters and especially my wonderful mother, who was so important in my life, were around me. Suddenly, through the images of the moment, there came the consideration, "I will be dead." Then I saw a telegram or letter messenger who gave my mother, at the door of her house, the notice of my death. She together with the other members of my family took the news with the deepest sorrow, but with pious greatness of soul. They showed no complaining, wailing or weeping. (Noyes, 1972, p. 175)

Of course, as is now well known, Heim not only survived this incident but, because of it, became intensely interested in what we now call NDEs and over the next 25 years interviewed some 30 others who, like himself, had survived near-fatal falls or other life-threatening incidents, and eventually published his findings in an obscure Swiss mountain climbing yearbook (Heim, 1892).

Whether the instances that Walker, Serdahely, and Bechtel cited, or these that I've just mentioned, involved glimpses of an alternate future track that would have actually occurred if the individual had died, or whether they have a more prosaic psychological explanation, is a question that must be left open for now. What seems clear, however, is that such apparent premonitions are hardly new to the near-death literature, but, on the contrary, can be found among the first narratives that now are known to mark the beginning of our modern field of near-death studies. In view of this fact, one wonders how many other such undiscovered cases might still remain to come to light. I hope the work of Walker, Serdahely, and Bechtel will help to spur such a search.

\section{References}

Audette, J.R. (1982). Historical perspectives on near-death episodes and experiences. In C.R. Lundahl (ed.), A collection of near-death research readings (pp. 21-43). Chicago, IL: Nelson-Hall.

Heim, A. (1892). Notizen uber den Tod durch Absturz. Jahrbuch des Schweitzer Alpenclub, 27, 327-337.

Noyes, R., Jr. (1972). The experience of dying. Psychiatry, 35, 174-184. 
Walker, B.A., Serdahely, W.J., and Bechtel, L.J. (1991). Three near-death experiences with premonitions of what could have been. Journal of Near-Death Studies, 9, 189 196.

Kenneth Ring, Ph.D. Department of Psychology University of Connecticut Storrs, CT 06269-1020 